\title{
Microbiological Quality of Chicken's Thigh After Vacuum Packaging and Fir Essential Oil Treatment
}

ISSN: 2637-7659

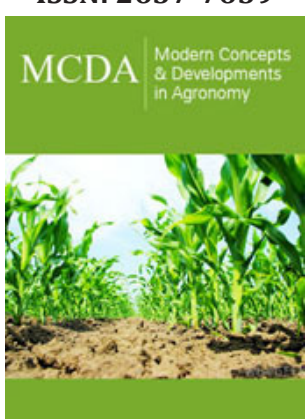

*Corresponding author: Kačániová M, Department of Microbiology, Faculty of Biotechnology and Food Sciences, Slovak Republic

Submission: 望 February 27, 2019

Published: 㭗 March 20, 2019

Volume 4 - Issue 1

How to cite this article: Kačániová $M$ Kluz C, Puchalski C, Mellen M, Vukovič N, et al. Microbiological Quality of Chicken's Thigh After Vacuum Packaging and Fir Essential Oil Treatment. Mod Concep Dev Agrono.4(1). MCDA.000577.2019.

DOI: 10.31031/MCDA.2019.04.000577

Copyright@ Kačániová $M$, This article is distributed under the terms of the Creative Commons Attribution 4.0 International License, which permits unrestricted use and redistribution provided that the original author and source are credited.

\section{Kačániová $\mathrm{M}^{1,2 *}$, Kluz $\mathrm{C}^{2}$, Puchalski $\mathrm{C}^{2}$, Mellen $\mathrm{M}^{3}$, Vukovič N4, Haščík $\mathrm{P}^{5}$ and Kunová $S^{6}$}

${ }^{1}$ Department of Microbiology, Slovak Republic

${ }^{2}$ Department of Bioenergy Technology and Food Analysis Faculty of Biology and Agriculture, Poland

${ }^{3}$ Klas holding, Slovakia

${ }^{4}$ Department of Chemistry, Faculty of Science, Serbia

${ }^{5}$ Department of Storing and Processing Plant Products, Slovak Republic

${ }^{6}$ Departmnet of Food Hygiene and Safety, Slovak Republic

\begin{abstract}
The aim of the present study was to monitor the fresh chicken thighs microbiological quality after treatment by sunflower oil and Abies alba essential oil in two concentrations, stored under vacuum packing (VP), at $4 \pm 0.5^{\circ} \mathrm{C}$ for a period of 16 days. There were used the following treatments of chicken thighs: Air-packaged (AC, control samples), vacuum-packaged (VPC, control samples), vacuum-packed with sunflower oil (SOC, control samples), VP with Abies alba essential oil at concentrations $0.1 \% \mathrm{v} / \mathrm{w}$ $(\mathrm{VP}+\mathrm{A} 0.1)$ and concentration $0.2 \% \mathrm{v} / \mathrm{w}(\mathrm{VP}+\mathrm{A} 0.2)$. The quality assessment of $\mathrm{VP}$ of the product in accordance with the terms above and sunflower oil treatment, Abies alba oil was established by microbiological analyze. The microbiological properties as the total viable counts and coliform bacteria, lactobacilli and Pseudomonas spp. were monitored. The using of Abies alba oil and sunflower oil with combination of vacuum packing has significant effect to reduction of microorganisms compared with control group without vacuum packing and untreated control group.
\end{abstract}

Keywords: Abies alba; Essential oil; Sunflower oil; Antimicrobial; Chicken thigh

\section{Introduction}

Essential oils (EOs) obtained from various herbs are widely used in cosmetics and food manufacturing and can be used for prolonging the shelf-life of food for their antibacterial, antifungal and antioxidant activities. EOs has inhibitory affect against microorganisms, are aromatic oily liquids obtained from the different plants material, which can be preparing by expression, fermentation, extraction etc. [1] and can contain aliphatic hydrocarbons, acids, alcohols, aldehydes, acyclic esters or lactones [2]. Beside essential oil from oregano, thyme, sage, rosemary, which are the most active in this respect against a number of food spoilage and pathogen microorganisms $[1,3,4]$ is possible use EOs from different resources as trees Pinaceae, which includes many of the well-known conifers of commercial importance. Pinaceae obtained polyphenolic compounds [5]. The chemical substances are terpenoids [6,7]. The composition of Abies sp. essential oil was observed many authors [8-12]. The main components of essential oils of Abies species are: $\alpha$-pinene, $\beta$-pinene, camphene, limonene and $\delta$-3-carene. These substances have significant antibacterial activities [13,14]. It is possible that these essential oils identified from the coniferous trees can be used antibacterial or antifungal agents in foods or in other products.

Guidelines specifically for marketing active and intelligent materials and articles intended for contact with food were published on May 29, 2009 (Regulation No. 450/2009) in the Official Journal of the EU and came into effect on June 18, 2009. These provisions were based on the general requirements established in 2004 in Framework Regulation (Regulation (EC) 
No 1935/2004) for the safe use of active and intelligent packaging materials. According to this regulation, 'active materials and articles' are defined as "materials and articles that are intended to extend the shelf-life or to maintain or improve the condition of packaged food; they are designed to deliberately incorporate components that would release or absorb substances into or from the packaged food or the environment surrounding the food" [15]. The topic of this study was to examine the conjunct effect of sunflower oil and Abies alba essential oil at two different concentrations, on the microbiological quality of fresh chicken thighs stored under vacuum packaging (VP), at $4 \pm 0.5^{\circ} \mathrm{C}$ for a period of 16 days.

\section{Material and Methods}

\section{Preparation of samples}

The experiment was realized in the Slovak poultry farm (Hydinaren a.s., Zamostie). The used animals were Cobb chickens. Chickens were fattening for period of 42 days and transported to the laboratory of Slovak University of Agricultural in Nitra. Chicken meat of each experimental group was taken to evaluate their properties. The chicken fresh meat samples with essential oils were prepared:

a) Air-packaged (AC, control samples): Chicken thigh fresh meat was packed to polyethylene backs and stored under aerobic conditions in refrigerator.

b) Vacuum-packaged (VPC, control samples): Chicken thigh fresh meat was packed to polyethylene backs and stored under aerobic conditions in vacuum and in refrigerator.

c) Vacuum-packed with sunflower oil (SOC, control samples): Chicken thigh fresh meat was treated with sunflower oil for $1 \mathrm{~min}$ and packed to polyethylene backs and stored under aerobic conditions in vacuum and in refrigerator.

d) Vacuum-packed with Abies alba oil $0.10 \%$ v/w (VP+A0.1): Chicken thigh fresh meat was treated with Abies alba oil for 1 min and packed to polyethylene backs and stored under aerobic conditions in vacuum and in refrigerator.

e) Vacuum-packed with Abies alba oil $0.20 \% \mathrm{v} / \mathrm{w},(\mathrm{VP}+\mathrm{A} 0.2)$ : Chicken thigh fresh meat was treated with Abies alba oil for $1 \mathrm{~min}$ and packed to polyethylene backs and stored under aerobic conditions in vacuum and in refrigerator.

Each sample was packaged using a vacuum packaging machine type VB-6 (RM Gastro, Czech Republic) immediately after dipping. Sunflower oil was purchased in a shop. Abies alba essential oil (Calendula, Nova Lubovna, Slovakia) was added to the coated chicken thigh surface (both sides) of each sample using a micropipette so as to achieve a $0.1 \%$ and $0.2 \% \mathrm{v} / \mathrm{w}$ final concentration of EO in sunflower oil.

\section{Essential oil sample preparing and chemical composition}

The medicinal plant for essential oil isolation was donated by successful and established growers. Essential oil was distilled in the large-scale distillation apparatus specifically designed for aromatic and medicinal plants. There are known two types: Type HV-3000 (height: $5.250 \mathrm{~mm}$, width: $2.180 \mathrm{~mm}$, with container for 200 or $250 \mathrm{~kg}$ of dried matter of 400 or $500 \mathrm{~kg}$ of fresh matter of plant material) and Type HV-300 (height: $3.400 \mathrm{~mm}$, width: $1.300 \mathrm{~mm}$, with container for 40 or $50 \mathrm{~kg}$ of dry matter and 100 or $120 \mathrm{~kg}$ of fresh matter of plant material). This large-scale technology of essential oil distillation in this Slovak company consists from the main distillatory apparatus, a steam condenser, and additional apparatuses (steam boiler and apparatus for improving of used water). Analysis of the essential oils was carried out using a HewlettPackard 5890/5970 GC-MSD system. Chemical composition of Abies alba oil was as follow: bornyl acetatte (30\%), camphene (18\%), $\alpha$-pinene (3\%), borneol (1.5\%), $\alpha$-terpinene (1.2\%).

\section{Microbiological analysis}

Approximately $10 \mathrm{~g}\left(10 \mathrm{~cm}^{2}\right)$ of the chicken meat was sampled in sterile condition, add to a sterile stomacher bags, with $90 \mathrm{~mL}$ of $0.1 \%$ peptone water ( $\mathrm{pH} 7.0$ ), and homogenized for 60s in a Stomacher at room temperature. Time intervals for measuring samples were 0 , 4, 8, 12 and 16 day. Meat from chickens were stored under vacuum packing, at $4 \pm 0.5{ }^{\circ} \mathrm{C}$. For microbiological analyses were using standard microbiological methods. Total viable counts (TVC) were evaluated on Plate Count Agar (PCA, Oxoid, UK), with incubation for 2 days at $37^{\circ} \mathrm{C}$. For Pseudomonas spp. enumerations, $0.1 \mathrm{~mL}$ from 1:10 prepared serial dilutions ( $0.1 \%$ physiological solution) of chicken homogenates was spread onto the surface of solid media. Pseudomonas were evaluated on Pseudomonas Isolation agar (PIA, Oxoid, UK) after incubation at $48 \mathrm{~h}$ at $25{ }^{\circ} \mathrm{C}$ with formation of blue or blue-green pyocyanin pigment for Pseudomonas aeruginosa identification. Lactobacillus spp. were enumerated in $1.0 \mathrm{~mL}$ of samples were on Rogosa and Sharpe agar (MRS, Oxoid, UK) after incubation $48-78 \mathrm{~h}$ at $37{ }^{\circ} \mathrm{C}$ in an aerobic atmosphere supplemented with carbon dioxide $\left(5 \% \mathrm{CO}_{2}\right)$. For members of the family Enterobacteriaceae, a $1.0 \mathrm{~mL}$ sample was inoculated into $10 \mathrm{~mL}$ of molten $\left(45^{\circ} \mathrm{C}\right)$ violet red bile glucose agar (VRBL, Oxoid, UK). After setting, a $10 \mathrm{~mL}$ overlay of molten medium was added and samples incubated at $37^{\circ} \mathrm{C}$ for $24 \mathrm{~h}$. The large colonies with purple haloes were counted. All plates were examined for typical colony types and morphology characteristics associated with each growth medium.

\section{Statistical analysis}

Statistical analysis of each replication were enumerated to log. The data obtained from each evaluation was implemented by means with Statgraphics Plus version 5.1 (AV Trading, Umex, Dresden, Germany). A statistical analysis was performed with Student's t-test. Differences were expressed as $\mathrm{P}<0.05 ; \mathrm{P}<0.01 ; \mathrm{P}<0.001$.

\section{Results and Discussion}

Many centuries we are know about the antimicrobial effect of essential oil. The number of total anaerobe bacteria count (TAB) values for the tested groups of chicken meat are in Figure 1. The initial TAB value of chicken meat was $2.90 \pm 0.23 \log _{\text {cfug }}{ }^{-1}$ (day 0 ), what can show good quality under the limit for poultry products of $10^{7} \mathrm{cfug}^{-1}$ [16]. Ismail et al. [17] found in TVC number from 3.32 to $5.77 \log _{\text {cfug }^{-1}}$ for chicken products. A high fat content appears to 
markedly reduce the action of EOs in meat products. The highest TVC in control samples and vacuum packaging control samples ranged from $3.71 \pm 0.11 \log _{\text {cfug }}{ }^{-1}$ to $3.75 \pm 0.17 \log _{\text {cfug }^{-1}}$ (day 16). In the study of Economou et al. [18] was evaluated, that total viable counts (TVC), Pseudomonas spp., Brochothrix thermosphacta, lactic acid bacteria (LAB) and Enterobacteriaceae counts for all EDTAtreated chicken samples were similar to the control samples with no statistically significant differences among combination nisinEDTA treatments. EDTA treatments did not affect TVC growth in agreement [19-21] Dawson et al. [22] reported a reduction in growth of aerobic bacteria by 1-1.5 $\operatorname{log~cfug}^{-1}$ in ground chicken meat after 14 days of storage under modified atmosphere packaging. Hyeusoo et al. [23] reported that the essential oils from the three Pinus species ( $P$. densiflora, $P$. thunbergii and P. rigida) showed higher antimicrobial activity against Gram-negative bacteria than Gram-positive bacteria.

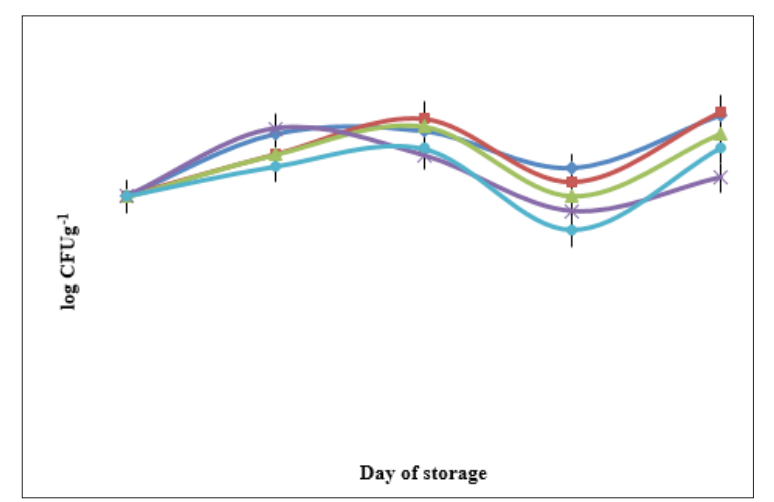

Figure 1: Changes (log cfug-1) in population of Total Viable Count in chicken thigh stored in air (AC, $\bullet)$; stored under vacuum (VP, $\mathbf{a})$; stored under vacuum packaging with sunflower oil (SOC, $\Delta)$; stored under vacuum packaging with Abies alba $0.1 \%$ essential oil $(\mathrm{VP}+\mathrm{A} 0.1, \times)$; stored under vacuum packaging with Abies alba $0.2 \%$ essential oil $(\mathrm{VP}+\mathrm{A} 0.2, \bullet)$. Each point is the mean of three samples taken from two replicate experiments $(n=3 \times 2=6)$. Error bars show SD.

Bağci and Diğrak [24] found that the antimicrobial activity of essential oils of Abies species varied at different concentrations against bacteria and yeasts. The antimicrobial activities of essential oils used were found to be more active against yeasts than bacteria. Statistically significant difference $(\mathrm{P}<0.05)$ was found between $\mathrm{AC}$ and $\mathrm{VP}+\mathrm{A} 0.1$ and $\mathrm{AC} ; \mathrm{AC}$ and $\mathrm{VP}+\mathrm{A} 0.2$. Other authors found bacteria from the Enterobacteriaceae family on raw beef, lamb, pork, and poultry products, as well as on offal meats [25]. The essential oil of Pinus densiflora did not inhibit the activity of $E$. coli, while the essential oils from $P$. thunbergii and $P$. rigida displayed antimicrobial activity against $E$. coli. Previous work showed that the essential oils from $P$. densiflora and $P$. thunbergii had moderate inhibitory activity, and were observed that the essential oil from P. roxburghaii did not affect the growth of E. coli $[26,27]$.

Bağci and Diğrak [24] tested antimicrobial activity of essential oils of nine Abies species (include A. alba) against nine bacteria (include E. coli and P. aeruginosa) and two yeasts. The essential oil of Abies alba classed into group which has higher effective on microorganisms. Microorganisms E. coli and $S$. aureus were the most resistant bacteria except for against $A$. koreana, A. cilicica subsp. isaurica and little $A$. alba and A. firma essential oils. Little antibacterial activity, $\alpha$ of silver essential oil-pinene was found against the growth of microorganism [28] and borneol and p-cymene show antibacterial effect too [29,30]. Di Pasqua et al. [31] reported that antimicrobial compounds including limonene has antibacterial activity against E. coli, S. aureus, S. ententerica, P. fluorescens, and B. thermosphacta cells. Antimicrobial activity against $S$. aureus was found with silver fir oil. Bacterial species from Enterobacteriaceae family as a hygiene indicator were evaluated $[32,33]$. In our study (day 0 ) the number of counts were $0.33 \pm 0.81$ $\log \mathrm{cfu} / \mathrm{g}$ what is indicator of well chicken's meat. On day 16 of storage Enterobacteriaceae genera reached $4.75 \pm 0.19 \log _{\mathrm{cfug}^{-1}}$ in control samples. In the case VP, the count of Enterobacteriaceae ranged from $0.33 \pm 0.81 \mathrm{log}_{\text {cfug }}{ }^{-1}$ (day 0 ) to $3.90 \pm 0.57 \operatorname{log~cfug}^{-1}$ (day 16). The number of Enterobacteriaceae $0 \log _{\text {cfug }}{ }^{-1}$ was found all the time of testing in the VP group with 0.1 and $0.2 \%$ Abies alba essential oil was (Figure 2).

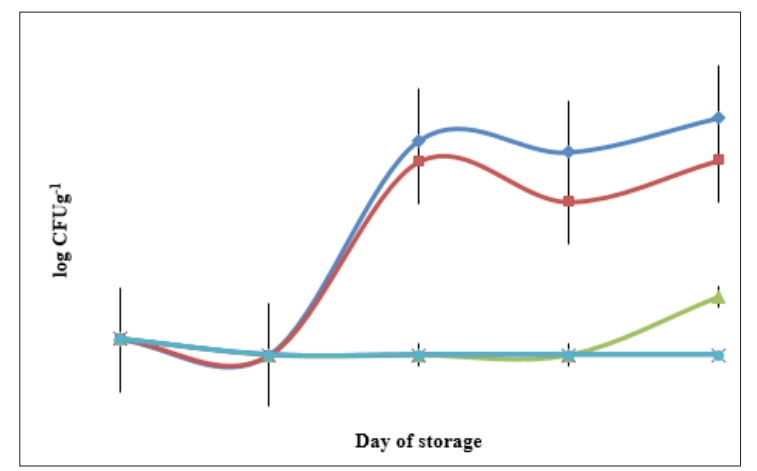

Figure 2: Changes (log cfug-1) in population of Enterobacteriacae in chicken thigh stored in air $(\mathrm{AC}, \bullet)$; stored under vacuum (VP, $\mathbf{m})$; stored under vacuum packaging with sunflower oil (SOC, $\Delta)$; stored under vacuum packaging with Abies alba $0.1 \%$ essential oil $(\mathrm{VP}+\mathrm{A} 0.1, \times)$; stored under vacuum packaging with Abies alba $0.2 \%$ essential oil $(\mathrm{VP}+\mathrm{A} 0.2, \bullet)$. Each point is the mean of three samples taken from two replicate experiments $(n=3 \times 2=6)$. Error bars show SD.

The number of Enterobacteriaceae 1.16 $\pm 1.80 \log _{\text {cfug }}{ }^{-1}$ only in 16 day of evaluation was indicated in the case of the storage under the package with sunflower oil groups. Statistically significant difference $(\mathrm{P}<0.05)$ was found between all tested group without $\mathrm{VP}+\mathrm{A} 0.1$ and $\mathrm{VP}+\mathrm{A} 0.2 ; \mathrm{VP}+\mathrm{A} 0.1$ and SOC and $\mathrm{VP}+\mathrm{A} 0.2$ and SOC. Lactic acid bacteria are facultative anaerobes and grow under concentrations of $\mathrm{CO}_{2}$. These bacteria are part of the microflora of meats used anaerobic condition. LABs are the important strains of the spoiled microbial species with anaerobic conditions [3335]. Particularly, Lactobacillus spp., Carnobacterium spp. and Leuconostoc spp. are microorganisms with spoiled character $[36,37]$. Lot of species of lactobacilli can be found during the storage under the vacuum condition at $4{ }^{\circ} \mathrm{C}$ including Lb. algidus beyond Lb. sakei. Ntzimani et al. [37] obtained that LAB was an important microbiota of the chicken meat in anaerobic condition. The rapid growth of LABs between days 0 and 2 of storage under MAP at $5{ }^{\circ} \mathrm{C}$ 
were evaluated [38]. The total counts of Lactobacillus sp. (Figure 3) was $1.88 \pm 0.49 \log _{\mathrm{cfug}^{-1}}$ (day 0). The number of Lactobacillus sp. in control group was ranged from $1.88 \pm 0.49 \log _{\text {cfug }^{-1}}$ (day 0 ) to $4.16 \pm 0.07 \log _{\text {cfug }^{-1}}$ (day 8).

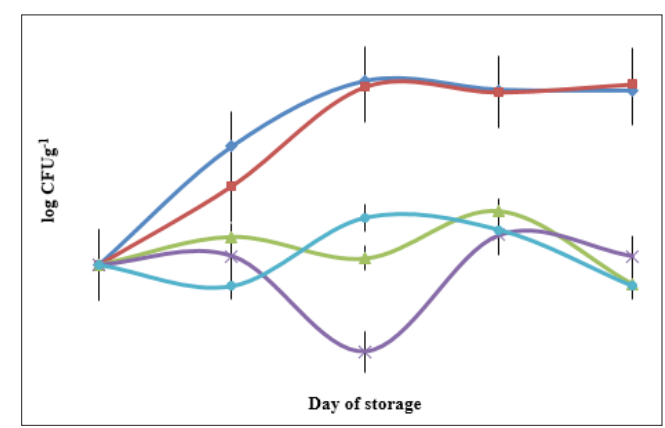

Figure 3: Changes (log cfug-1) in population of Lactobacillus sp. in chicken thigh stored in air $(\mathrm{AC}, \bullet)$; stored under vacuum $(\mathrm{VP}, \mathbf{-})$; stored under vacuum packaging with sunflower oil (SOC, $\Delta)$; stored under vacuum packaging with Abies alba $0.1 \%$ essential oil $(\mathrm{VP}+\mathrm{A} 0.1, \times)$; stored under vacuum packaging with Abies alba $0.2 \%$ essential oil (VP+A0.2, •). Each point is the mean of three samples taken from two replicate experiments $(n=3 \times 2=6)$. Error bars show SD.

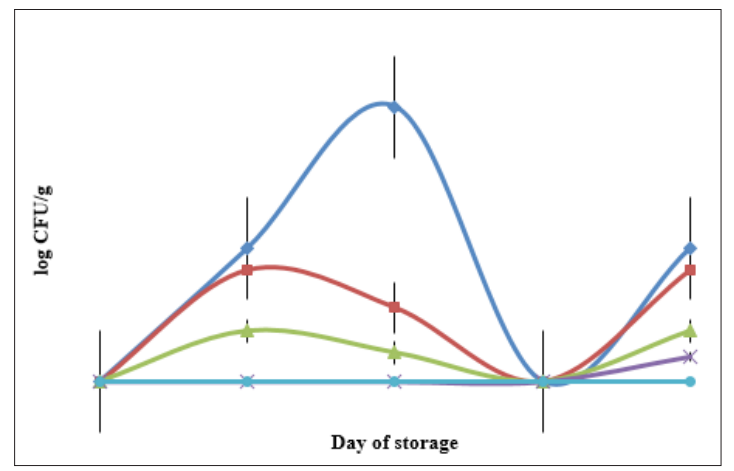

Figure 4: Changes (log cfug-1) in population of Pseudomonas spp. in chicken thigh stored in air (AC, $\bullet)$; stored under vacuum (VP, $\mathbf{a})$; stored under vacuum packaging with sunflower oil (SOC, $\Delta)$; stored under vacuum packaging with Abies alba $0.1 \%$ essential oil $(\mathrm{VP}+\mathrm{A} 0.1, \mathrm{x})$; stored under vacuum packaging with Abies alba $0.2 \%$ essential oil (VP+A0.2, •). Each point is the mean of three samples taken from two replicate experiments $(n=3 \times 2=6)$. Error bars show SD.

In the case VP group, the highest count of Lactobacillus sp. $4.12 \pm 0.04$ log cfug $^{-1}$ was marked on day 16 of storage; in SOC group 2.55 $\pm 0.30 \log _{\mathrm{cfug}^{-1}}$ (day 12); in $\mathrm{VP}+\mathrm{A} 0.1$ group $2.25 \pm 0.38$ $\log \mathrm{cfug}^{-1}$ (day 12) and VP+A0.2 2.46 $\pm 0.60 \log _{\mathrm{cfug}^{-1}}$ (day 8) [39]. Statistically significant difference $(\mathrm{P}<0.05)$ was found between $\mathrm{AC}$ and SOC; SOC and VP; VP+A0.1 and AC; VP+A0.1 and VP; VP+A0.2 and AC; VP+A0.2 and VP. Several gram-negative bacteria, including Pseudomonads, and $P$. aeruginosa, are not very resistant against of EOs [40]. Bioactive components of plant-origin antimicrobials are relatively weak against Pseudomonas spp. Various studies show the opposite effect of essential oils against gram-positive bacteria [1]. The essential oils from leaves of the three Pinus species inhibited the bacterial growth. The essential oils from $P$. thunbergii and $P$. rigida showed bactericidal activity at $4 \mathrm{~h}$. Previous work showed that the essential oils from $P$. densiflora and $P$. thunbergii had slight inhibitory activity and the essential oil from $P$. caribeae exhibited antimicrobial activity [40]. In our study the initial count of Pseudomonas spp. was $0 \pm 0.00 \log _{\mathrm{cfug}^{-1}}$ (day 0 ) and the highest numerous amount was $3.65 \pm 0.12 \log _{\mathrm{cfug}^{-1}}$ (day 8 ) in the control group; $1.47 \pm 1.15 \log _{\text {cfug }^{-1}}$ (day 4 ) in VP group; $0.67 \pm 1.03$ log cfug-

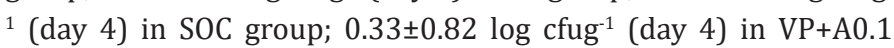
group and in $\mathrm{VP}+\mathrm{A} 0.2$ group was no presented $P$. aeruginosa during all testing period. It is very interesting, that all tested groups the numerous of $P$. aeruginosa was $0 \log \mathrm{cfu} / \mathrm{g}$ on $12^{\text {th }}$ day of the study. The statistically significant differences $(P<0.05)$ were found between AC and SOC; AC and VP; VP+A0.1 and AC; AP+A0.1 and VP; $\mathrm{VP}+\mathrm{A} 0.2$ and $\mathrm{AC} ; \mathrm{AP}+\mathrm{A} 0.2$ and $\mathrm{VP}$.

\section{Conclusion}

Our results show the potential antimicrobial effect of the Abies alba essential oil be natural food preservatives and antimicrobial sources for chicken meat. The use of our treatment with sunflower oil and Abies alba essential oil have good antimicrobial activity against the growth of Pseudomonas spp., Lactobacillus spp. and Enterobactericeae genera and decrease total viable count. Microbiological analyses of Abies alba essential oil treatments show better microbiological quality of chicken's meat compare with control samples. Combined effect of essential oil and vacuum packaging should be investigated on the safety and hygienic quality of chicken's meat.

\section{Acknowledgment}

This work has been supported by the grant of the European Union project no. 26220220180: Building Research Centre "AgroBioTech" and the grant of Slovak Research and Development Agency No. VEGA 1/0411/17.

\section{References}

1. Douglas M (2015) Sources of data.

2. Chen Wu-Jun et al. (2010) Appraising enterprise technology innovation project. University of Toyama, Japan.

3. Gao Q Zhang C (2011) Analysis of innovation capability of agricultural hi-technology industries in China. Journal of Innovation: Management policy and practice 3(3): 278-290.

4. Wang Z (2007) Technological innovation capacity index system. Economic conference, Wuhan University of Science and Technology, Hubei Wuhan, China.

5. Petit M (2015) Sustainable agricultural development: Challenges and approaches in southern and eastern mediterranean countries. Springer.

6. Hao Y, Farooq Q Zhang Y (2018) Unattended social wants and corporate social responsibility of leading firms: Relationship of intrinsic motivation of volunteering in proposed welfare programs and employee attributes. Corporate Social Responsibility and Environmental Management 25(6): 1029-1038. 
7. Farooq Q, Fu P, Hao Y, Jonathan T, Zhang Y (2019) A review of management and importance of e-commerce implementation in service delivery of private express enterprises of china. SAGE Open 9(1).

8. Farooq Q, Hao Y, Liu X (2019) Understanding corporate social responsibility with cross-cultural difference: A Deeper Look at Religiosity. Corporate Social Responsibility and Environmental Management.

9. Zhang L, Farooq Q Zhang Y, Liu X, Hao Y (2019) Fair value and mispricing: How domestic earnings transparency of listed firms leads to global financial stability. European Journal of International Management.

10. Adedigba A (2017) 2018 budget: Buhari allocates 7\% to education.

11. Vanguard Newspaper (2018) 67\% Nigerians live below poverty linepresidential aide.
12. Dandam GG (2017) Plateau state project coordinator, National Fadama Project, speech on "Agriculture and National development in Nigeria: An Appraisal of the National Fadama Project.

13. Asoegwu SN, Asoegwu AO (2007) An overview of agricultural mechanisation and its environmental management in Nigeria International Commission of Agricultural Engineering: CIGR E-Journal $9(6): 5$.

14. Usman SK (2017) Agriculture and national development in Nigeria: An appraisal of the National FADAMA project. p.50.

15. Company Overview of Dupont (China) Research \& Development and Management Co Ltd.

16. FAO (2015) How to feed the world in 2050. p. 5.

For possible submissions Click below: 